\title{
Sequencing of the Litchi Downy Blight Pathogen Reveals It Is a Phytophthora Species With Downy Mildew-Like Characteristics
}

\author{
Wenwu Ye, ${ }^{1}$ Yang Wang, ${ }^{1}$ Danyu Shen, ${ }^{1}$ Delong Li, ${ }^{1}$ Tianhuizi Pu, ${ }^{1}$ Zide Jiang, ${ }^{3}$ Zhengguang Zhang, ${ }^{1}$ \\ Xiaobo Zheng, ${ }^{1}$ Brett M Tyler, ${ }^{2}$ and Yuanchao Wang ${ }^{1}$ \\ ${ }^{1}$ Department of Plant Pathology, Nanjing Agricultural University, Nanjing 210095, China; ${ }^{2}$ Center for Genome Research and Biocomputing, \\ and Department of Botany and Plant Pathology, Oregon State University, Corvallis, OR 97331, U.S.A.; and ${ }^{3}$ Guangdong Province \\ Key Laboratory of Microbial Signals and Disease Control, South China Agricultural University, Guangzhou 510642, China
}

Accepted 10 May 2016.

\begin{abstract}
On the basis of its downy mildew-like morphology, the litchi downy blight pathogen was previously named Peronophythora litchii. Recently, however, it was proposed to transfer this pathogen to Phytophthora clade 4. To better characterize this unusual oomycete species and important fruit pathogen, we obtained the genome sequence of Phytophthora litchii and compared it to those from other oomycete species. $P$. litchii has a small genome with tightly spaced genes. On the basis of a multilocus phylogenetic analysis, the placement of $P$. litchii in the genus Phytophthora is strongly supported. Effector proteins predicted included 245 RxLR, 30 necrosis-and-ethyleneinducing protein-like, and 14 crinkler proteins. The typical motifs, phylogenies, and activities of these effectors were typical for a Phytophthora species. However, like the genome features of the analyzed downy mildews, $P$. litchii exhibited a streamlined genome with a relatively small number of genes in both core and species-specific protein families. The low GC content and slight codon preferences of $P$. litchii sequences were similar to those of the analyzed downy mildews and a subset of Phytophthora species. Taken together, these observations suggest that $P$. litchii is a Phytophthora pathogen that is in the process of acquiring downy mildew-like genomic and morphological features. Thus $P$. litchii may provide a novel model for investigating morphological development and genomic adaptation in oomycete pathogens.
\end{abstract}

Litchi (or lychee; Litchi chinensis) is a tropical and subtropical fruit tree extensively grown in China, Southeast Asia, the Indian Subcontinent, and, more recently, South Africa, Brazil, the Caribbean, Queensland, California, and Florida (Crane et al. 2005; Mitra and Pathak 2008; Morton 1987). Phytophthora litchii, formerly Peronophythora litchii (Chen 1961; Göker et al. 2007), causes significant pre- and postharvest crop losses due to litchi downy blight disease. P. litchii can attack fruit, panicles, and new shoots of litchi, causing panicle rot as well as withering and watery brown spots of fruits (Ann and Ko 1984; Vien et al. 2001; Wang et al. 2010).

Corresponding author: Y. Wang; E-mail: wangyc@njau.edu.cn; Telephone: +86 25 84399071; Fax: +862584395325.

*The $\boldsymbol{e}$-Xtra logo stands for "electronic extra" and indicates that 12 supplementary figures and 13 supplementary tables are published online.

๑) 2016 The American Phytopathological Society
P. litchii is an oomycete, a group that shares the kingdom Straminipila with photosynthetic algae such as diatoms (thus, is distinctive from fungi) and that includes many pathogens of plants and animals. However, the precise taxonomy of $P$. litchii has long been ambiguous. It produces Peronospora-like sporangiophores but can grow on artificial media (Supplementary Fig. S1). On the one hand, the differentiated, branched, and determinate sporangiophores of $P$. litchii suggest a taxonomic affinity with downy mildews such as Peronospora species. On the other hand, the mode of zoospore release from the sporangia, the morphology of the sex organs, and the ability to grow on artificial media are consistent with an affinity with Phytophthora spp. Due to its transitional features, P. litchii was previously named as Peronophythora litchii (Chen 1961), and the family Peronophythoraceae, containing only a single genus (Peronophythora) and species ( $P$. litchii), was subsequently established to accommodate this ambiguous species (Ko et al. 1978). But later, this species was suggested to be a Phytophthora species and was renamed as Phytophthora litchii according to its morphology during asexual reproduction (Chi et al. 1982; Ho et al. 1984; Huang et al. 1983). More recently, the taxonomic status of $P$. litchii was re-evaluated via phylogenetic analysis of the sequences of large subunit ribosomal DNA sequences (D1 and D2 region), ribosomal intergenic transcribed spacer and $28 \mathrm{~S}$ sequences, and multiple genes, and nearly all these analyses supported the idea that $P$. litchii is a Phytophthora species (Göker et al. 2007; Riethmüller et al. 2002; Voglmayr 2003; Zhang et al. 2007). The most recent reports placed this species in clade 4 of the genus Phytophthora (Göker et al. 2007; Kroon et al. 2012).

Although some basic biological characteristics of $P$. litchii have been described, the molecular mechanisms of pathogen development and infection have not been elucidated in this unusual oomycete and important litchi pathogen. Here, we have sequenced the genome of $P$. litchii and compared it to other oomycete genomes. The results reveal a number of genomic characteristics in common with downy mildews as well as many in common with Phytophthora species.

\section{RESULTS}

P. litchii has a small genome with tightly spaced genes.

Genomic DNA of $P$. litchii was sequenced using Illumina paired-end sequencing technology. A total of $3.2 \mathrm{~Gb}$ of clean reads were generated and assembled into 2,543 scaffolds, with a total assembly length of $38 \mathrm{Mb}$ and an $\mathrm{N}_{50}$ scaffold length of 
$35 \mathrm{~kb}$ (Supplementary Table $\mathrm{S} 1$ ). The repeated sequence content and genome size were estimated to be $33 \%$ and $58 \mathrm{Mb}$, respectively (Supplementary Fig. S2). The difference between the assembly length and the estimated genome size is likely due to poor assembly of repeat-rich regions. Based on the core eukaryotic genes mapping approach (CEGMA) pipeline, P. litchii orthologs could be identified for $97 \%$ of the 248 conserved single-copy eukaryotic genes, suggesting that the genome assembly encompassed nearly the complete gene space (Supplementary Fig. S3).

A total of 13,155 gene models were predicted, with an average length of $1,648 \mathrm{bp}, 1.6$ introns per gene, and an average intergenic space of 1,241 bp within the $38 \mathrm{Mb}$ length of the assembly. The mean gene length and intron number were similar to other sequenced Phytophthora genomes, except that of $P$. capsici (Table 1). The estimated repeated sequence content was comparable to many other oomycetes, with the exception of P. infestans and Pythium ultimum (Table 1). However, the estimated genome size was smaller than most of the analyzed oomycete genomes, except those of P. capsici and Pythium ultimum, while the gene number and average intergenic space were the smallest of any of the oomycetes (Table 1).

The distributions of intergenic region lengths were compared among the above organisms (Fig. 1). As noted above, genes in the $P$. litchii genome appeared tightly spaced, around 346 genes per Mb, which was similar to Pythium ultimum (Fig. 1A and B) and more closely spaced than the other analyzed Phytophthora (Fig. 1C and D) and downy mildew (Fig. 1E through G) genomes.

\section{Low GC content and slight codon preference.}

Among 11 oomycete genomes, the $\mathrm{G}+\mathrm{C}$ content (GC content or \%GC) of the P. litchii assembly (49\%) was the lowest of all the Phytophthora genomes but higher than those of the downy mildews (Table 1; Supplementary Fig. S4A). We further compared GC content in gene-coding and non-gene coding regions as well as codon first, second, and third positions of gene-coding regions (\% GC1, \%GC2, and \%GC3, respectively). In general, the coding regions of each species exhibited higher \%GC values than those of the noncoding regions. However, across the 11 species, \%GC values of coding and noncoding regions exhibited strong positive correlation $\left(\mathrm{R}^{2}=0.79\right)$, indicating that the bias of GC content among the species was genome wide. In addition, $\%$ $\mathrm{GC}$ values of the coding regions were most correlated with \%GC of the codon third position $\left(\mathrm{R}^{2}=0.99\right)$. In nearly all species, the codon third position exhibited the strongest preference for $\mathrm{G}$ or $\mathrm{C}$ and the largest range of values among the analyzed species. In contrast, the \%GC values of the first and second codon positions were slightly higher and much lower than the overall coding regions, respectively.

Table 1. Genome statistics of Phytophthora litchii and other oomycetes ${ }^{\mathrm{a}}$

\begin{tabular}{|c|c|c|c|c|c|c|c|c|c|c|}
\hline Categories & Phl & Phs & Phr & Phi & Phc & $P y u$ & Hya & Pet & Plh & Sap \\
\hline Estimated genome size (Mb) & 58 & 95 & 65 & 240 & 57 & 45 & 99 & 68 & 100 & 63 \\
\hline Assembly size $(\mathrm{Mb})$ & 38 & 86 & 67 & 229 & 64 & 43 & 82 & 63 & 75 & 53 \\
\hline $\mathrm{G}+\mathrm{C}$ content $(\%)$ & 49 & 54 & 54 & 51 & 50 & 52 & 47 & 48 & 45 & 58 \\
\hline Repeat $(\%)$ & 33 & 39 & 28 & 74 & 19 & 7 & 35 & 24 & 39 & 40 \\
\hline Number of genes & 13,155 & 19,027 & 15,743 & 17,797 & 19,805 & 15,297 & 14,567 & 18,447 & 15,469 & 17,065 \\
\hline Gene length mean (bp) & 1,648 & 1,614 & 1,624 & 1,525 & 1,253 & 1,503 & 1,113 & 1,250 & 1,143 & 1,521 \\
\hline Mean intergenic distance (bp) & 1,241 & 2,906 & 2,632 & 11,342 & 1,979 & 1,308 & 4,516 & 2,171 & 3,705 & 1,585 \\
\hline Mean introns per gene & 1.6 & 1.6 & 1.6 & 1.8 & 1.2 & 1.6 & 1.0 & 2.3 & 2.6 & 3.0 \\
\hline
\end{tabular}

${ }^{a}$ Phl, Phytophthora litchii; Phs, Phytophthora sojae; Phr, Phytophthora ramorum; Phi, Phytophthora infestans; Phc, Phytophthora capsici; Pyu, Pythium ultimum; Hya, Hyaloperonospora arabidopsidis; Pet, Peronospora tabacina; Plh, Plasmopara halstedii; and Sap, Saprolegnia parasitica.
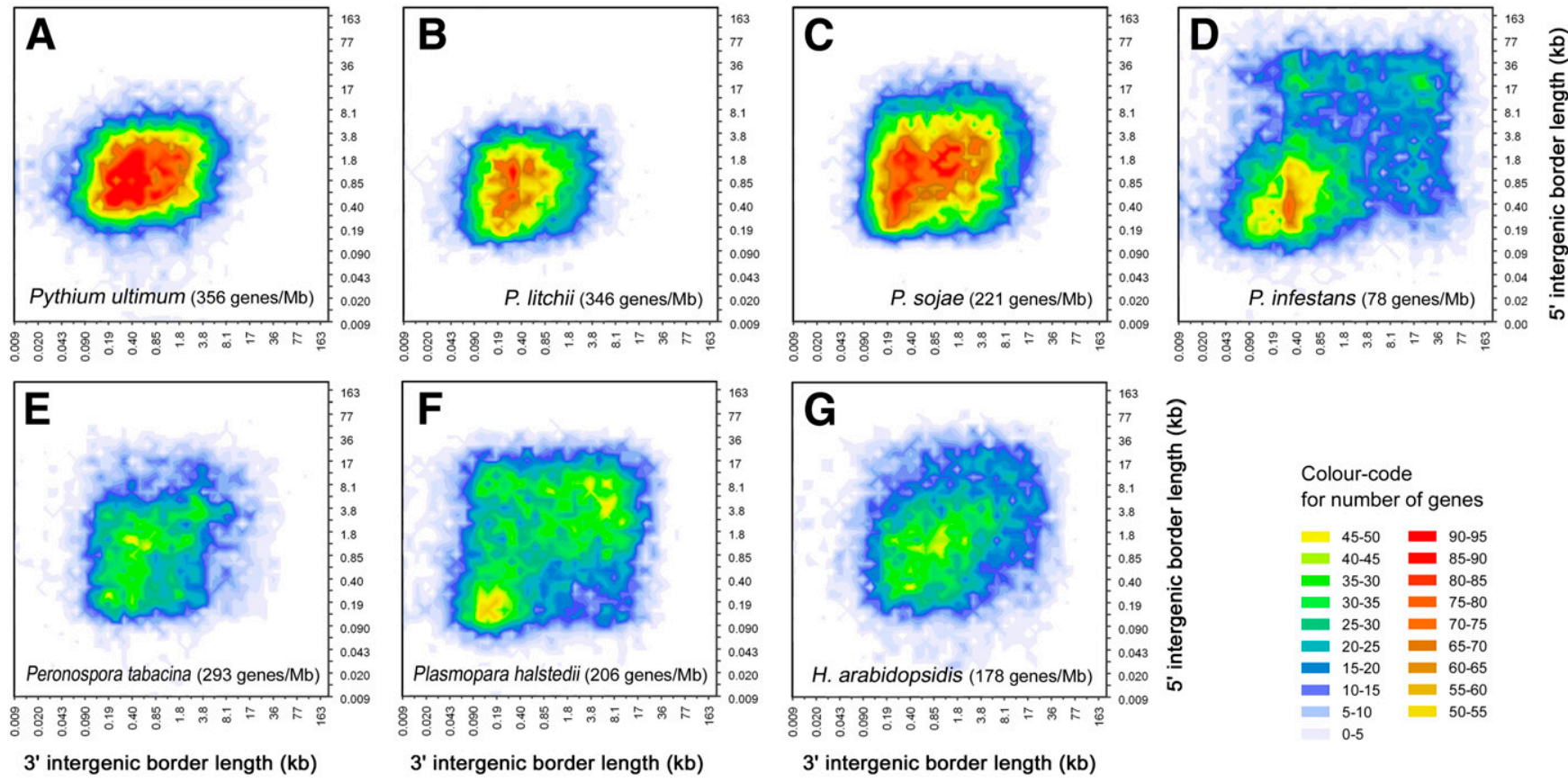

Fig. 1. Distribution of intergenic region lengths in Phytophthora litchii compared with other oomycetes. A, Pythium ultimum, B, P. litchii, C, P. sojae, D, P. infestans, E, Peronospora tabacina, F, Plasmopara halstedii, and $\mathbf{G}$, Hyaloperonospora arabidopsidis. The flanking distance between neighboring genes provides a measurement of local gene density. Values in brackets show the average number of predicted genes per megabase of assembled genome sequences. 
Next, we calculated relative synonymous codon usage (RSCU) values for each of the species (Supplementary Table S2). We clustered the patterns of RSCU values according to both codons and species, using hierarchical (HCL) methods (Fig. 2A). Nearly all codons ending with $\mathrm{G}$ or $\mathrm{C}$ had high RSCU values (greater than 1, indicating that the codon was more frequent than expected; Plasmopara halstedii was an exception), indicating a considerable preference for codons ending with $\mathrm{G}$ or $\mathrm{C}$ (Fig. 2A). Those codons were clustered in a group. Among the species, $P$. sojae, $P$. ramorum, and Pythium ultimum formed one cluster, while $P$. litchii, $P$. infestans, $P$. parasitica, P. capsici, Hyaloperonospora arabidopsidis, and Peronospora tabacina formed a second cluster. Plasmopara halstedii and Saprolegnia parasitica were outliers (Fig. 2A). We also analyzed the patterns of RSCU values among the species, using principal component analysis (PCA) (Fig. 2B). Again, the results revealed that the species exhibited two major groups, according to high versus low GC content and strong versus slight codon pre ference. The three downy mildews clustered with four of the Phytophthora species, namely P. litchii, P. infestans, P. parasitica, and $P$. capsici, with Plasmopara halstedii the most outlying member of this cluster. These seven species exhibited low GC content and slight codon preference. Pythium ultimum, P. sojae, and $P$. ramorum formed a second cluster with higher GC content and stronger bias, while $S$. parasitica remained an outlier (Fig. 2B).

\section{Multigene phylogenetic analysis confirms $P$. litchii is in Phytophthora clade 4.}

Phylogenetic trees of 12 genome-sequenced oomycete species were constructed, based on 293 core genes identified by the CEGMA pipeline. Both the concatenated DNA sequences of the genes and the concatenated amino acid sequences encoded by the genes were analyzed. Before constructing trees using RaxML, PartitionFinder software was used to select best-fit partitioning schemes and models of molecular evolution for nucleotide and amino acid alignments, respectively. The trees constructed using protein and DNA sequences and considering one single partition and multiple partitions displayed nearly identical topological structures. The downy mildews formed a cluster nested within the Phytophthora clade, and P. litchii was nested in a subcluster of the Phytophthora clade that was close to the downy mildew cluster (Fig. 3A). Consistent with the phylogenies reported in some previous studies (Göker et al. 2007; Riethmüller et al. 2002; Voglmayr 2003), this placement of $P$. litchii added evidence in support of the theory that $P$. litchii is a Phytophthora species. Furthermore, a recent phylogenetic analysis of the genus Phytophthora (Martin et al. 2014) was repeated, incorporating corresponding sequences from the $P$. litchii genome assembly. Two trees, constructed using five nuclear (Supplementary Fig. S5A) or four mitochondrial loci, supported the idea that $P$. litchii is in clade 4 of the genus Phytophthora.

\section{Protein sequence identity and gene colinearity with Phytophthora genomes.}

In order to evaluate the overall sequence similarity of $P$. litchii proteins with those of other oomycetes and stramenopiles, all 13,155 predicted protein sequences of $P$. litchii were compared with translated genome sequences of the other species, using a TBLASTN search with 1e-8 as the E-value cut-off. The largest numbers of $P$. litchii protein sequences matched the translated genome sequences of the six Phytophthora species, while lower matches were observed to those of the other five oomycete species. Even lower numbers of matches were observed to protein sequences from the stramenopile diatom Phaeodactylum tricornutum and the fungus Magnaporthe
A

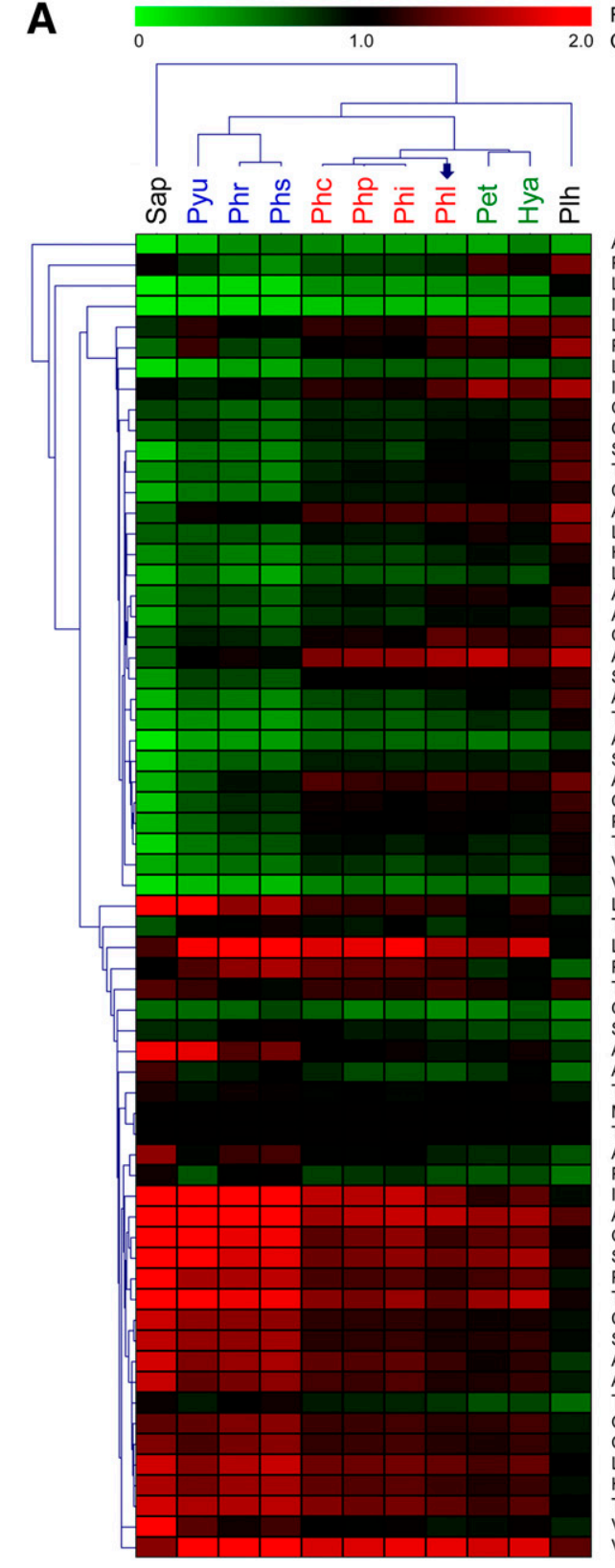

Relative Synonymous Codon Usage (RSCU)

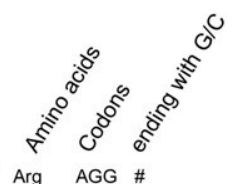

Arg AGG

Phe UUU

Leu UUA
lle AUA

Leu UUG \#

Pro CCA

Leu CUA

lle AUU

$\begin{array}{ll}\text { Gln } & \text { CAA } \\ \text { Glu } & \text { GAA }\end{array}$

Ser UCA

Thr ACA
Cys UGU

Arg CGA

Leu CUU

$\begin{array}{ll}\text { His } & \text { CAU } \\ \text { Lys AAA }\end{array}$

Ala GCA

$\begin{array}{ll}\text { Asp } & \text { GAU } \\ \text { Gly } & \text { GGU }\end{array}$

Arg CGU

Ser AGU

$\begin{array}{ll}\text { Asn } & \text { AAU } \\ \text { Tyr } & \text { UAU }\end{array}$

$\begin{array}{ll}\text { Tyr } & \text { UAU } \\ \text { Arg } & \text { AGA }\end{array}$

Arg AGA

Ala GCU

Pro CCU

Thr ACU
Val GUU

Val GUU
Val GUA

Leu CUC \#

TER UGA

Leu CUG \#

TER UAA

Gly GGG \#

$\begin{array}{lll}\text { Ser } & \text { UCC } & \# \\ \text { Ala } & \text { GCG } & \#\end{array}$

Ala Arg CGG \#

TER UAG \#
Met AUG \#

$\begin{array}{lll}\text { Trp } & \text { UGG \# } \\ \text { Ala } & \text { GCC \# }\end{array}$

Pro CCC \#

$\begin{array}{lll}\text { lle } & \text { AUC \# } \\ \text { Arg } & \text { CGC \# }\end{array}$

Arg CGC \#

Ser UCG \#

Pro ACG \#

Cys UGC \#

AGC \#

AAC \#

ACC \#

CAG \#

GAG \#

AAG \#

CAC \#

UAC \#

GUC \#

B

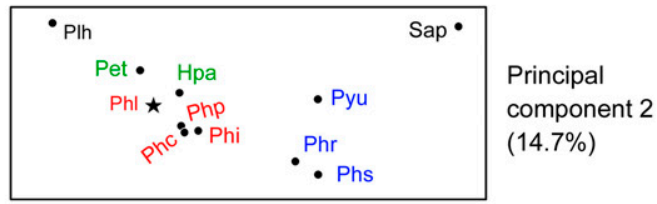

Principal component $1(79.2 \%)$

Fig. 2. Clustering of species and codons according to the relative synonymous codon usage (RSCU) values. A, Heat map of RSCU values clustered according to species and codons. Red and green colors indicate RSCU values higher and lower than 1, indicating strong and weak preference for codon usage, respectively. \# indicates codons that end with $\mathrm{G}$ or C. The labels of species were colored according to the clustering results. B, Based on RSCU values, the species were clustered using principal components analysis. Principal components 1 and 2 together represent $93.9 \%$ of the eigenvalues. Sap, Saprolegnia parasitica; Pyu, Pythium ultimum; Phr, P. ramorum; Phs, P. sojae; Phc, P. capsici; Php, P. parasitica; Phi, P. infestans; Phl, Phytophthora litchii; Pet, Peronospora tabacina; Hya, Hyaloperonospora arabidopsidis; Plh, Plasmopara halstedii. The colors of labels are the same as those in A. 
oryzae (Fig. 3B). Across the spans of the matched regions, the $P$. litchii protein sequences showed a median identity of more than $71 \%$ with the corresponding sequences from each Phytophthora genome, whereas the median identities between the $P$. litchii and downy mildew sequences ranged from 66 to $69 \%$. Lower median identities were observed for protein sequences from Pythium ultimum (56\%) and S. parasitica (45\%) and even lower for Phaeodactylum tricornutum and M. oryzae (Fig. 3C).

As a comparison, the same TBLASTN search was performed using all predicted protein sequences from $P$. sojae against the genome sequences of $P$. infestans and $P$. litchii. There were similar numbers of matched $P$. sojae proteins and similar median sequence identities with the $P$. infestans and $P$. litchii genomes (Fig. 3B and C), supporting the theory that the sequences of the P. litchii proteins are similar to those of the other Phytophthora species.

We used DAGchainer to examine gene colinearity between the $P$. litchii genome and the other oomycete genomes. The numbers of $P$. litchii genes showing colinearity were greatest in the comparison with Phytophthora species (7,047 and 6,531 with $P$. infestans and $P$. sojae, respectively) and least with H. arabidopsidis $(3,240)$ (Supplementary Fig. S6; Supplementary Table S3). There were 678 and 637 blocks of colinearity with the two Phytophthora genomes with, respectively, 10.4 and 10.3 genes per block on average. In contrast, there were only 394 blocks of colinearity with the $H$. arabidopsidis genome with 8.2 genes per block. Thus, the genes of $P$. litchii exhibited much greater colinearity with the genes in the Phytophthora genomes.

\section{Genes for nitrate, nitrite, and sulfite reduction are retained in $P$. litchii.}

In the obligate biotroph $H$. arabidopsidis and the oomycete fish pathogen $S$. parasitica, genes for nitrate and nitrite reductases, a nitrate transporter, and sulfite reductase are absent (Baxter et al. 2010; Jiang et al. 2013). Similar genes have been lost from obligate fungal pathogens (Spanu et al. 2010). In two recently available downy mildew assemblies, none of the five genes could be found in Plasmopara halstedii but, interestingly, two sulfite reductase genes could be identified in Peronospora tabacina (Supplementary Table S4; Supplementary Fig. S7A). In contrast to these downy mildews, all five genes could be readily identified from the $P$. litchii genome assembly, as in other Phytophthora species. The existence or absence of certain genes was confirmed in the gene colinearity analysis. A phylogenetic analysis of these five $P$. litchii proteins relative to those from other Phytophthora species and their most identical homologs from other eukaryotes supported the idea that the P. litchii proteins shared a common origin with the other Phytophthora proteins.

\section{P. litchii gene families have fewer members than other Phytophthora species.}

To learn why the $P$. litchii genome had a reduced number of genes, we used TribeMCL (Enright et al. 2003) to cluster the predicted proteins of $P$. litchii, $P$. sojae, P. infestans, $H$. arabidopsidis, and Pythium ultimum into families (Supplementary Table S5). We discovered that $P$. litchii shared more clustered protein groups (Fig. 4A) and group members (Fig. 4B) with $P$. infestans and $P$. sojae than with $H$. arabidopsidis and Pythium ultimum. Approximately $60 \%$ of the predicted proteins in each species were clustered into groups that contained at least one member (Fig. 4C). However, the average numbers of proteins per group were different, ranging from 2.69 in $P$. sojae and 2.40 in P. infestans to 1.98 in P. litchii and 1.91 in $H$. arabidopsidis (Fig. 4D). The clustering also identified variable numbers of proteins that were species-specific. In $P$. sojae and $P$. infestans, 6.5 and $8.7 \%$ of the proteins, respectively, were species-specific. In contrast, only $1.11 \%$ of the genes in P. litchii were species-specific but $22 \%$ of the genes in $H$. arabidopsidis were species-specific (Fig. 4E). The average numbers of proteins per group ranged from 1.70 in $P$. sojae and 1.75 in $P$. infestans to 1.11 in $P$. litchii and 1.13 in H. arabidopsidis (Fig. 4F).
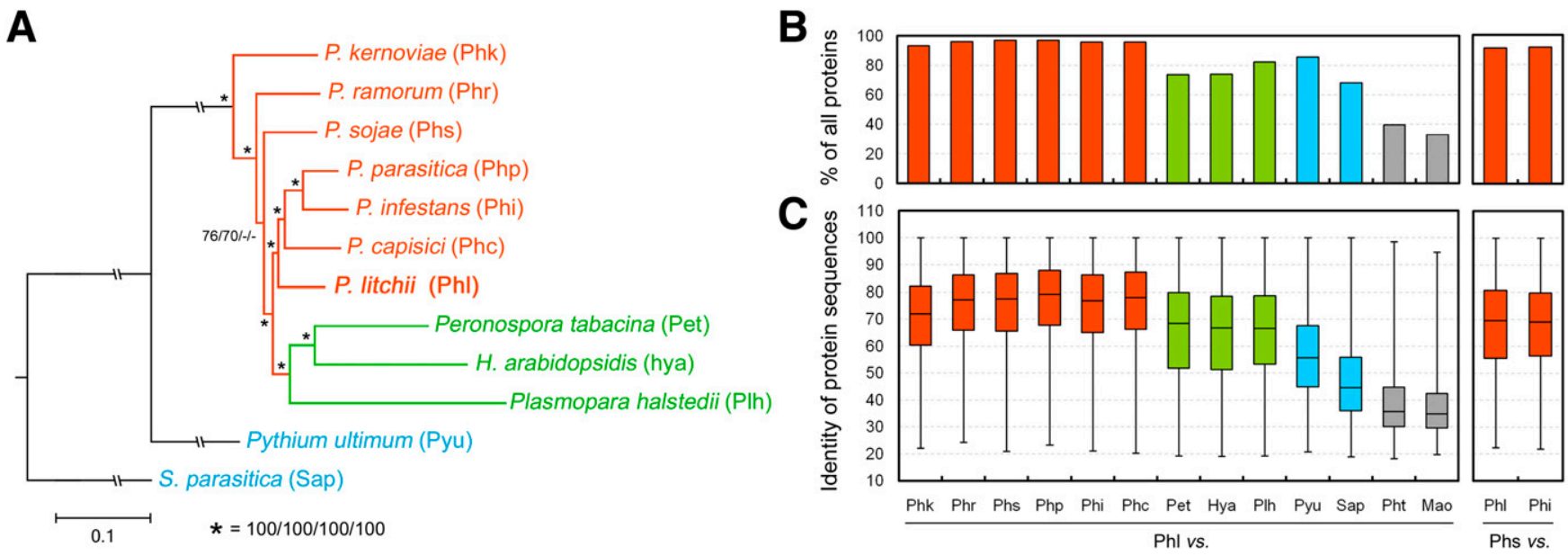

Fig. 3. Phylogenetic analysis and comparisons of protein sequence identity. A, Multisequence phylogenetic tree constructed by RaxML (ML + rapid bootstrap method with 200 bootstrap repeats), using concatenated DNA or protein sequences of 293 core genes identified by CEGMA analysis. The topology of the tree was nearly identical, irrespective of whether the DNA or amino acid sequences were used or whether one single position or multiple positions were evaluated Numbers near branches denote bootstrap values based on (from left to right): protein sequences, 182 PartitionFinderProtein-suggested positions, LG+G model; protein sequences, one single position, LG+G+F model; DNA sequences, 114 PartitionFinder-suggested positions, GTR+G model; DNA sequences, one single position, GTR+G model. Asterisks indicate $100 \%$ bootstrap by all four methods. B, The columns show the proportions of Phytophthora litchii or P. sojae proteins that have TBLASTN hits $(<1 \mathrm{e}-8)$ against the genome of each listed species. C, The boxplots show distributions of $P$. litchii or $P$. sojae proteins having different percent identities within TBLASTN alignments with translated genome sequences from each listed species. The bottom and top of the box represent the first and third quartiles and the band inside the box represents the median. The whisker ends represent the minimum and maximum of all data. Phk, Phytophthora kernoviae; Phr, P. ramorum; Phs, P. sojae; Php, P. parasitica; Phi, P. infestans; Phc, P. capsici; Pet, Peronospora tabacina; Hya, Hyaloperonospora arabidopsidis; Plh, Plasmopara halstedii; Pyu, Pythium ultimum; Sap, Saprolegnia parasitica; Pht, Phaeodactylum tricornutum; and Mao, Magnaporthe oryzae; and Phl, Phytophthora litchii. In A through C, red indicates Phytophthora species, green indicates downy mildew species, blue indicates other oomycetes, and gray indicates nonoomycete species. 
We also compared the number of proteins mapped into PFAM protein families (Supplementary Table S6). Again, protein numbers per PFAM family in $P$. litchii were generally less than those in $P$. sojae, $P$. ramorum, and $P$. infestans and greater than those in H. arabidopsidis and Plasmopara halstedii (Supplementary Fig. S8A and B). Since P. litchii is a plant pathogen, we further checked the putative pathogenicityrelated PFAM families. The majority of these families had fewer or a comparable number of members than in the analyzed Phytophthora species but distinctly more members than in the analyzed downy mildews. We analyzed genes encoding potential cell wall-degrading enzymes (CWDE), including carbohydrate esterases, glycoside hydrolases, and polysaccharide lyases, and obtained similar results (Supplementary Table S7). Moreover, we searched for gene families expanded in $P$. litchii compared with other Phytophthora species, but no significant examples were found (data not shown). Overall, therefore, the results suggest that widespread reductions in gene family membership and in the number of species-specific genes might explain the fewer total number of genes in P. litchii.

\section{Families of virulence effectors.}

Phytophthora genomes are characterized by three large families of virulence effectors defined by distinctive sequence motifs, namely RxLR effectors (hundreds of members per genome), crinkler (CRN) effectors (tens to hundreds of members per genome), and necrosis-and-ethylene-inducing protein-like (NLP) effectors (tens of members per genome) (Haas et al. 2009; Tyler et al. 2006). Smaller numbers of these effector genes occur in downy mildews such as $H$. arabidopsidis (Baxter et al. 2010), Plasmopara halstedii (Sharma et al. 2015), and Peronospora tabacina (Derevnina et al. 2015). Distant relatives of CRN and NLP effectors can be found in fungi (Joneson et al. 2011) and fungi and bacteria (Gijzen and Nurnberger 2006), respectively, while RxLR effector genes appear specific to Phytophthora and downy mildew species - none at all could be found in seven surveyed Pythium genomes (Adhikari et al. 2013; Lévesque et al. 2010). In $P$. litchii, we identified candidates for these three effector families, including 245 RxLR (Supplementary Table S8), 30 NLP (Supplementary Table S9), and 14 CRN (Supplementary Table S10) proteins. These candidate effector proteins contained sequence features and motifs characteristic of the respective effector families (Supplementary Fig. S9A to D). The numbers of CRN and NLP effector gene candidates were comparable to those of the other Phytophthora species, though at the low end of the range in each case (Supplementary Table S11). The number of RxLR effector candidates was somewhat fewer than the other Phytophthora species but almost twofold greater than those of downy mildews, e.g., 134 in $H$. arabidopsidis
A

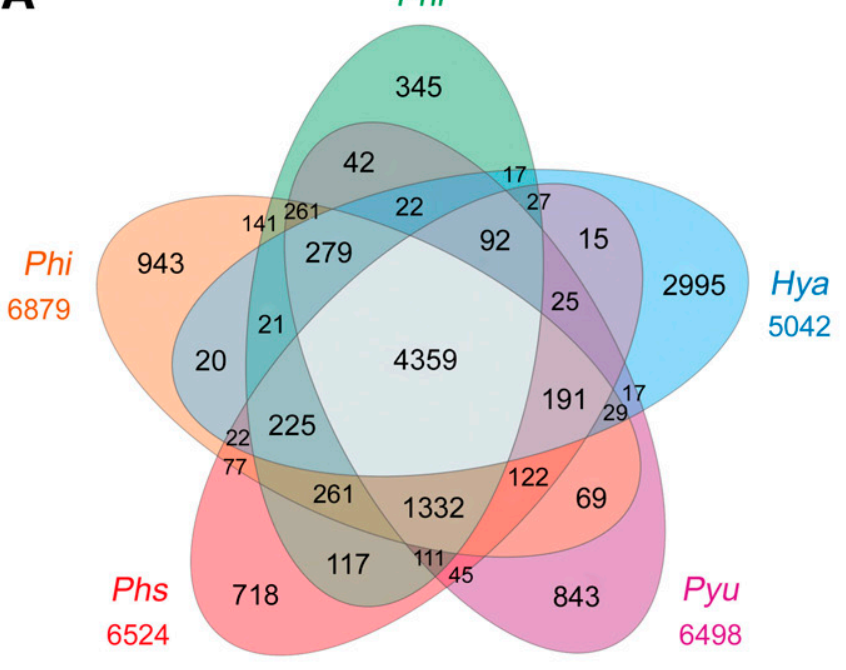

Clustered protein groups
B

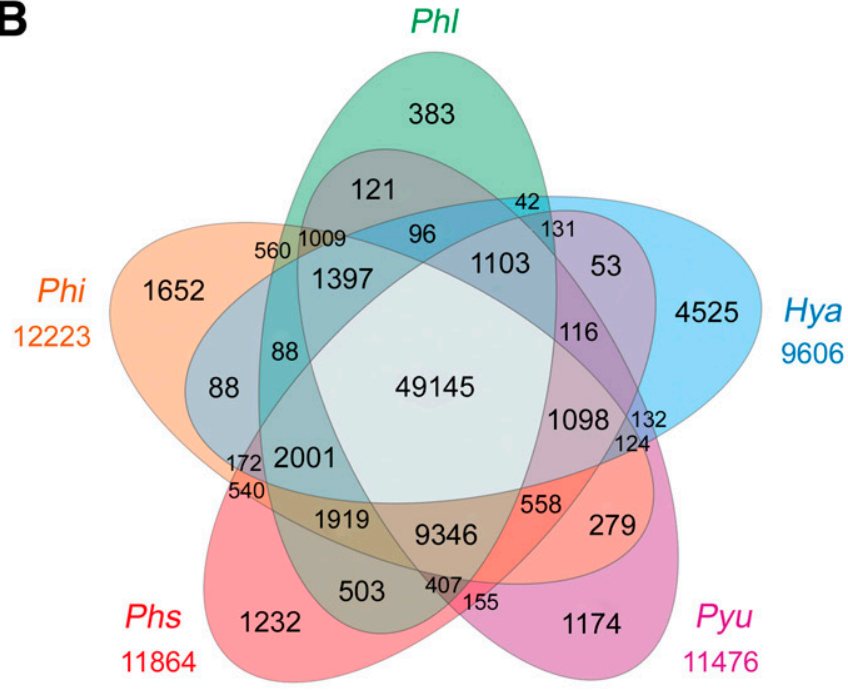

Proteins in the groups

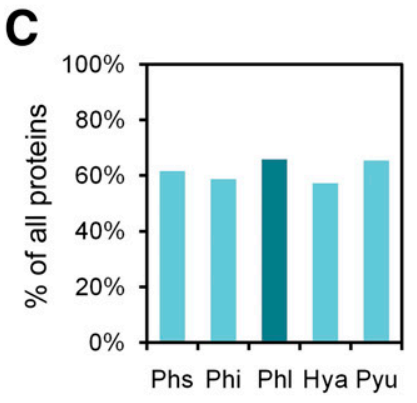

D

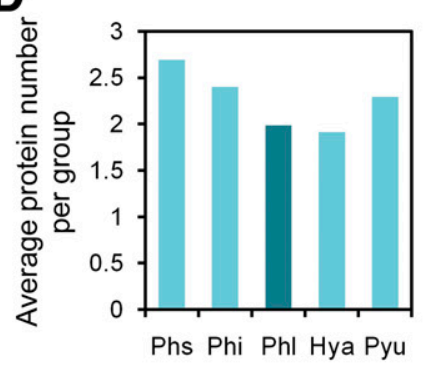

Proteins shared across all species

E

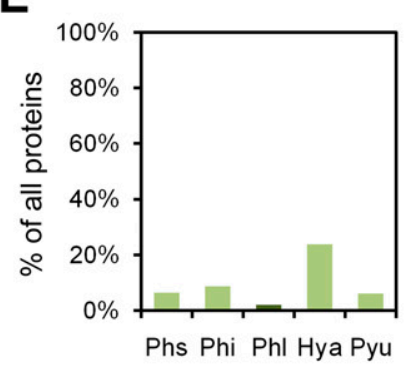

$\mathbf{F}$

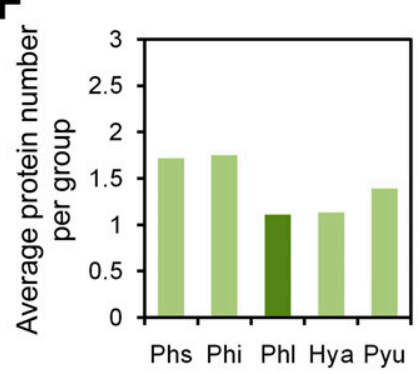

Species-specific proteins

Fig. 4. Comparison of oomycete protein groupings and group memberships. Numerals indicate the numbers of $\mathbf{A}$, clustered groups or $\mathbf{B}$, proteins in a group within a particular subset. The numerals outside the Venn diagrams indicate the total number shared between Phytophthora litchii and the indicated species. $\mathbf{C}$, Percentage of the predicted proteome of each species that is shared across all analyzed oomycete species. D, For each species, the average number of proteins per group is shown for proteins shared across all analyzed oomycete species. E, Percentage of the predicted proteome of each species that is specific to that species. F, For each species, the average number of proteins per group is shown for proteins specific to that species. Phs, P. sojae; Phi, P. infestans; Phl, P. litchii; Hya, Hyaloperonospora arabidopsidis; and Pyu, Pythium ultimum. 
(Baxter et al. 2010) and 120 in Peronospora tabacina (Derevnina et al. 2015).

A total of 265 candidates were originally identified from at least one of the two methods for prediction of RxLR effectors, i.e., hidden Markov model (HMM) and BLASTP (Supplementary Fig. S10A). Regular expression searches were further used to check if the candidates contained one or both "R/Q/GxLR" or "EER" strings at the 21st to 120th amino acids (aa) of protein sequences. All HMM candidates matched this regular expression, while 20 BLASTP candidates were excluded and were, thus, designated "RxLR-like" candidates. The remaining 245 proteins were defined as the $P$. litchii RxLR candidates. As in the RxLR effector family generally (Ye et al. 2015), the predicted secondary structures of these $P$. litchii RxLR proteins exhibited a high content of alpha-helices. In addition, the features of the typical motifs were more similar to those of the other Phytophthora RxLR proteins. Over half of the RxLR proteins in both $P$. litchii and other Phytophthora species contained both R/Q/GxLR and EER strings, while the proportions in $H$. arabidopsidis and Plasmopara halstedii were 35 and $14 \%$, respectively. Moreover, $76 \%$ of $P$. litchii RxLR protein sequences contained a perfect RxLR string within the identified RxLR motif. The top five patterns were RFLR, RLLR, RSLR, RHLR, and RRLR, accounting for $82 \%$ of those perfect RxLR strings. Those two percentages were comparable to those in P. sojae (79 and $78 \%$ ), $P$. ramorum (71 and $87 \%$ ), and $P$. infestans ( 82 and $81 \%$ ), but different to $H$. arabidopsidis (60 and 70\%), and Plasmopara halstedii (15 and 54\%) (Supplementary Table S12).

We also identified WY-domain effectors in P. litchii and obtained 92 candidates, made up of 87 RxLR and five RxLRlike candidates. Based on the same analysis of the other oomycete species, we found at least $89 \%$ of the WY-domain effector candidates in Phytophthora species contained the $\mathrm{R} / \mathrm{Q} / \mathrm{GxLR}$ and/or EER strings (most were the RxLR effector candidates), compared with only $67 \%$ of $H$. arabidopsidis WYdomain proteins, and 50\% in the case of Plasmopara halstedii. The WY-domain effectors comprised $36 \%$ of all P. litchii RxLR candidates, which was similar to the other Phytophthora RxLR candidates ( 35 to $45 \%$ ) but different from those of $H$. arabidopsidis $(28 \%)$ and Plasmopara halstedii $(4 \%)$. Thus, in line with the previous reports (Baxter et al. 2010; Derevnina et al. 2015; Sharma et al. 2015), we found the RxLR protein sequences of downy mildews exhibited more variability in the typical effector motifs, whereas the $P$. litchii RxLR proteins were more similar to those of the other Phytophthora species. As in other Phytophthora species (Jiang et al. 2008), the P. litchii WY-domain proteins were predicted to contain one to eight such domains in each sequence (Supplementary Fig. S11A), and the lengths of protein sequences were positively correlated with the numbers of WY-domain in each protein.

We identified 14 candidate members of the CRN effector family from the $P$. litchii genome assembly, based on HMM and BLASTP searches. Consistent with the previous reports that only a few CRN effectors contain a predicted signal peptide that can be recognized by the SignalP algorithm (Derevnina et al. 2015; Haas et al. 2009), we found there was only one such protein in P. litchii.

To evaluate the predicted NLP proteins encoded in the $P$. litchii genome, we constructed a maximum-likelihood tree, using available sequences from the oomycetes $P$. sojae, $P$. litchii, $H$. arabidopsidis, Peronospora tabacina, Plasmopara halstedii, and Pythium ultimum and the fungi M. oryzae and Fusarium graminearum (Fig. 5). The $P$. litchii sequences grouped closely with $P$. sojae sequences, in most cases in pairwise relationships and in some cases in small $P$. litchii-specific subclades. By comparison, the majority of the downy mildew and Pythium ultimum NLP sequences formed clades isolated from each other and from the major Phytophthora clade. The fungal NLP proteins formed an even more isolated clade.

In $P$. sojae, several NLP proteins exhibit necrosis-inducing activity when transiently expressed in Nicotiana benthamiana (Dong et al. 2012). All these NLP proteins are found in certain clusters (necrosis-inducing clusters) of clades in the tree shown in Figure 5, while outside these clusters, several tested $P$. sojae NLP proteins could not induce necrosis. We randomly selected $12 P$. litchii NLP effector candidates, including seven close to the necrosis-inducing clusters and five far from such clusters, to assay for induction of cell death in $N$. benthamiana. We found three of the first seven $P$. litchii NLP proteins could induce necrosis in N. benthamiana, while the other tested NLP proteins could not (Fig. 5; Supplementary Fig. S12). The results indicate that the NLP proteins of $P$. litchii and $P$. sojae may maintain similar functions or activities.

\section{DISCUSSION}

P. litchii is a well-known pathogen of litchi. Due to its downy mildew-like morphology, the taxonomic status of $P$. litchii used to be controversial. Furthermore, the genome information and molecular mechanisms of development and infection of this pathogen have not been examined. In this study, we determined the genome sequence of $P$. litchii and compared its phylogeny, genome size, gene number, gene colinearity, sequence identity, GC content, and codon usage, protein family sizes, and effector features to other oomycete species.

Several features of the $P$. litchii genome affirm that the recent transfer of this species to the genus Phytophthora is correct. First, multisequence phylogenies of genome-sequenced oomycete species based on 293 core genes unambiguously placed $P$. litchii within genus Phytophthora. Similar results were observed in other phylogenies constructed from specific genes. This conclusion is also supported by analysis of global protein sequence identity and of gene colinearity among the sequenced oomycete genomes. A further Phytophthora-like feature was the retention of genes for inorganic nitrogen and sulfur assimilation, which have been lost from the indicated downy mildews (partially lost in Peronospora tabacina) and S. parasitica genomes. Effector candidates of the RxLR, CRN, and NLP families could readily be identified in $P$. litchii, and the numbers of genes in these families and the sequence or motif features of these proteins were closer to those of Phytophthora species. In particular, phylogenetic analysis and necrosis-inducing activity assays of the NLP proteins of $P$. litchii showed them to have close affinity with Phytophthora NLP and to be distinct from the NLP from downy mildews and Pythium ultimum.

Despite the unambiguous identification of $P$. litchii as a Phytophthora species, a number of features of the P. litchii genome were distinctive and suggest it is subject to some of the evolutionary forces that have shaped downy mildew genomes. For example, the $P$. litchii genome was unexpectedly small in size and contained fewer genes than other sequenced Phytophthora genomes. The lower total number of genes appeared to result from smaller gene families and reduced numbers of species-specific genes, rather than the complete elimination of many gene families. The genomes of downy mildew pathogens such as H. arabidopsidis and Plasmopara halstedii are also streamlined and showed similar reductions in the sizes of gene families. For example, all the $P$. litchii, $H$. arabidopsidis, and Plasmopara halstedii genomes contain reduced numbers of CWDE. Reductions in the number of these particular enzymes may reflect adaptations for stealthy biotrophic growth. Both $P$. litchii and downy mildews also share relatively low GC content and mild codon preferences. However the significance of this feature is not clear. 
Some other Phytophthora species, such as P. infestans, also exhibit this relatively low GC content while others, such as $P$. sojae, have a distinctly higher GC content and strong codon preference.

The relationship of the genera of downy mildews, Phytophthora, and Pythium has been a matter of ongoing debate. Members of the genera Phytophthora and Pythium can, in general, be cultured on standard or nonstandard agar media. In contrast, the downy mildews are obligate biotrophs, since they have not, to date, been cultured on any artificial medium. Previously, genera Phytophthora and Pythium were grouped together in the family

\section{Phytophthora \\ - P. litchii \\ - P. sojae \\ Downy mildews \\ Pseudoperonospora cubensis \\ - Peronospora tabacina \\ Plasmopara halstedii \\ Pythium \\ A Pythium ultimum \\ Fungi \\ O Magnaporthe oryzae \\ $\diamond$ Fusarium graminearum \\ $\star$ Inducing necrosis \\ $\star$ NOT inducing necrosis}

Hyaloperonospora arabidopsidis
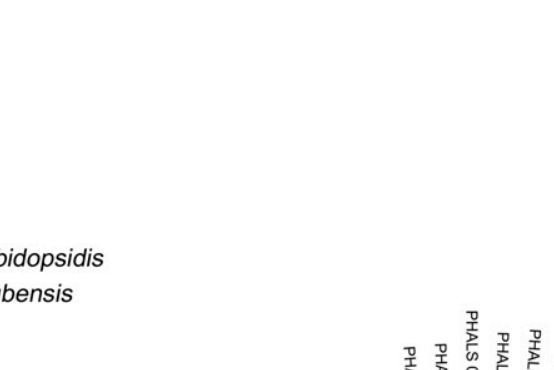

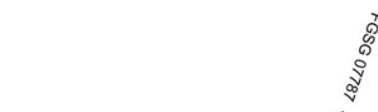
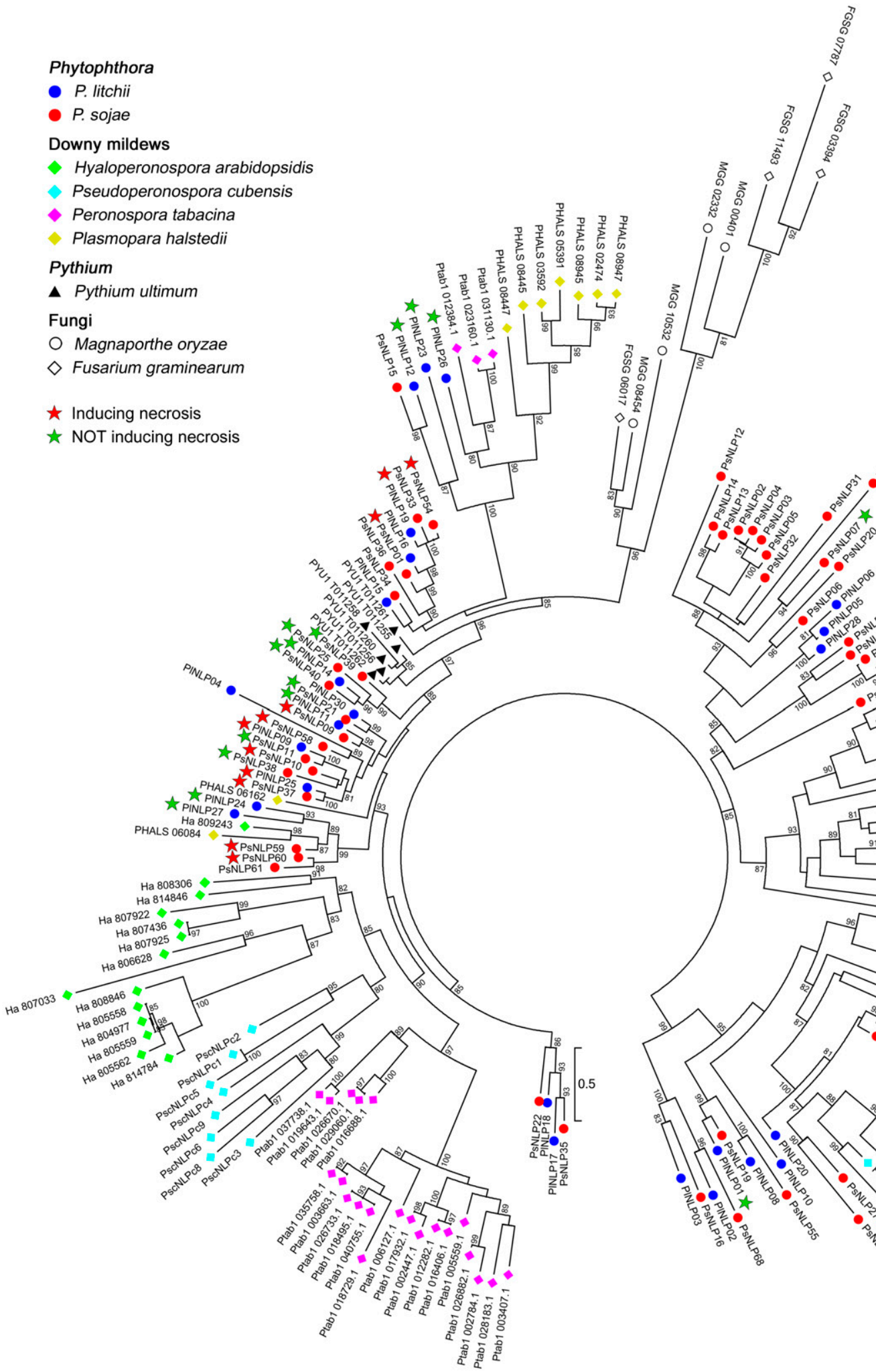

.7. 
Pythiaceae (Waterhouse 1973). More recently, however, analysis of large subunit rRNA gene sequences from 50 downy mildew species and 18 Phytophthora species suggested monophyly of a clade comprising both the genus Phytophthora and the downy mildews (Göker et al. 2007). That analysis and a later one involving the nucleotide sequences of seven genes from 80 Phytophthora species and two downy mildews (Runge et al. 2011) concluded that the genus Phytophthora was paraphyletic, while the downy mildew representatives were monophyletic and nested within Phytophthora clade 4, which contains P. litchii. Similar results were obtained in our study. The phylogenetic analysis, based on 293 orthologous protein-coding genes from seven Phytophthora species and three downy mildew species, supported the idea that the downy mildew clade was nested within genus Phytophthora and also showed that $P$. litchii was the nearest to the downy mildew cluster. The extended multilocus phylogenies of many Phytophthora species further confirmed that $P$. litchii is in clade 4 of the genus Phytophthora. Thus, it is tempting to suppose that the downy mildew-like morphological and genomic characteristics of $P$. litchii may be due to an ancestor shared with downy mildews within clade 4 and that $P$. litchii may have acquired downy mildew-like genomic and morphological features through a common ancestor with downy mildews. However, the phylogenetic position still might change with the addition of more Phytophthora and downy mildew genomes, due to the effect of incomplete taxon sampling; therefore, the phylogenetic data are not yet strong enough to rule out that $P$. litchii could have acquired these characteristics via convergent evolution.

The small genome size of $P$. litchii, including smaller gene family sizes, makes it an attractive model for molecular manipulation and investigation of the molecular mechanisms of development and infection of oomycete pathogens. We have already successfully executed polyethylene glycol-mediated protoplast transformation of $P$. litchii (unpublished). We have preliminarily identified experimentally tractable hosts for $P$. litchii, namely $N$. benthamiana and tomato (Solanum lycopersicum L.). Previous reports identified litchi as the only natural host of $P$. litchii, but this pathogen was recently found naturally infecting additional plants. For example, $P$. litchii could also cause leaf and stem blight on longan (Euphoria longana) seedlings (Ann et al. 2012), thus providing a range of hosts for experimental investigation of host range.

In conclusion, $P$. litchii represents an unusual Phytophthora species in which downy mildew-like morphological features have evolved independently from the true downy mildews, and several features of the genome have also acquired downy mildew-like characteristics. Its compact genome as well as its morphological and physiological features make P. litchii a novel potential model species with which to assess the environmental and host adaptability of oomycete pathogens during evolution.

\section{MATERIALS AND METHODS}

\section{Genome sequencing and assembly.}

The sequenced $P$. litchii strain SHS3 was isolated from Guangzhou Province, China. High-quality genomic DNA was prepared and submitted to the Beijing Genomics Institute for Illumina sequencing. Paired-end reads of $90 \mathrm{bp} \times 2$ in length and $500 \mathrm{bp}$ in insert size were generated. A total of 3,404 Mb of raw data, including 3,205 $\mathrm{Mb}$ of clean data, were obtained. The short reads were assembled into a genome sequence using SOAPdenovo (version 1.05). The key parameter, K, was 27. Assembled scaffolds from SOAPdenovo were further linked using SSPACE (version 1.1). Gap filling and single base corrections were performed via SOAPaligner (version 2.21). The final assembly was $38.2 \mathrm{Mb}$ in size and contained 2,543 scaffolds longer than $1,000 \mathrm{bp}$. The difference between the assembly size and the estimated genome size (58 Mb) likely results from poor assembly of the repeated sequences that comprise $33 \%$ of the genome. The CEGMA pipeline was used to compare the completeness and continuity of the genome (the Korf Lab, University of California-Davis). The sequence reads and assemblies have been deposited in GenBank (Bioproject ID: PRJNA290406).

\section{Gene annotation.}

Gene models were predicted from the assembly results using Augustus, trained with the 26,584 gene models of $P$. sojae (Joint Genome Institute [JGI] Phytophthora sojae v3.0 database). To classify protein families and identify CWDE, we used HMMER 3 to align the predicted protein sequences with HMMs for PFAM families (EMBL-EBI Pfam database) and from the Carbohydrate-active enzyme ANnotation (dbCAN) database. An E-value $<0.001$ was used for PFAM mapping. In dbCAN mapping, the following criteria were used: if alignment length $>80$ aa, use E-value $<1 \mathrm{e}-5$, otherwise use E-value $<1 \mathrm{e}-3$ and covered fraction $>0.3$. Covered fraction was calculated as (End - Start) divided by length of HMM.

To identify candidate effector proteins, the $P$. litchii genome sequences were translated to all possible open reading frames (ORF) that encoded 80 to 1,000 aa from both strands.

For identification of RxLR candidates, two methods were then used to search these ORF-coding proteins: i) a series of iterative HMM searches (score $>0$ ). The initial HMM profile was created on the basis of the $P$. sojae RxLR sequences, while subsequent searches used an HMM profile built from the novel sets of $P$. litchii RxLR candidates. The HMM profiles were built using the aligned protein sequences of RxLR or RxLR-EER motifs along with 5 to 10 aa before and after these motifs. Sequences were aligned using MAFFT (v7.221). And ii) a series of iterative BLASTP searches (E-value <1e-5), using available RxLR proteins from $P$. sojae, $P$. ramorum, $P$. infestans, and $H$. arabidopsidis as the first set of query sequences and the new identified $P$. litchii candidates as the next sets of query sequences. The candidates from $\mathrm{i}$ and ii were then checked to verify if they contained one or both R/Q/GxLR or EER strings within the region from the 21 st to 120 th residues of protein sequences.

For identification of WY-domain proteins and CRN candidates, we performed similar HMM searches, using an alignment of the available WY-domain or full-length $\mathrm{CRN}$ sequences from $P$. sojae, $P$. ramorum, and $P$. infestans (Boutemy et al. 2011; Haas et al. 2009). The HMM alignments for the newly identified CRN candidates were manually checked to see whether they contained typical LQLFLAK and HVLVVVP motifs.

For identification of NLP candidates, we conducted a BLASTP search, using the $P$. sojae NLP proteins as query sequences (Dong et al. 2012). The candidates were then manually checked to see if they contained typical GHRHDWE or -like motifs.

Candidate RxLR and NLP effectors but not CRN effectors (because many CRN candidates do not contain a signal peptide that is recognized by SignalP 3.0) (Haas et al. 2009) were also required to contain a predicted signal peptide, based on a threshold HMM score of $>0.9$ from SignalP 3.0 and to not contain a transmembrane domain (TMHMM 2.0) outside the signal peptide. Sequences of typical motifs were aligned using MAFFT (v7.221) and features of these motifs were illustrated using Weblogo.

\section{Comparative genomic analysis.}

Sequences of $P$. sojae (v1.1) (Tyler et al. 2006), P. ramorum (v1.1) (Tyler et al. 2006), P. capsici (LT1534 v11.0) (Lamour et al. 2012), and Phaeodactylum tricornutum (v2.051706) (Bowler et al. 2008) were obtained from the Department of Energy JGI database; P. infestans (T30-4) (Haas et al. 2009), 
P. parasitica (INRA-310), S. parasitica (CBS 223.65) (Jiang et al. 2013), and M. oryzae (MG8) (Dean et al. 2005) were obtained from the Broad Institute database; $P$. kernoviae (AOFI00000000.2) (Sambles et al. 2015) were obtained from the GenBank database; H. arabidopsidis (v8.3) (Baxter et al. 2010) were obtained from the Eumicrobedb database; Plasmopara halstedii were obtained from M. Thines (IPF, Bik-F, Senckenberg, Frankfurt, Germany) (Sharma et al. 2015); Peronospora tabacina (968-J2) were from the National Center for Biotechnology Information (BioProject: PRJNA285243) (Derevnina et al. 2015); Pythium ultimum (DAOM BR144, pug1) were obtained from the Pythium genome database (Lévesque et al. 2010).

Gene colinearity was analyzed using DAGchainer. As input into DAGchainer, BLASTP comparisons were performed using $1 \mathrm{e}-5$ as a cut-off E-value to identify candidate ortholog pairs. DAGchainer uses a list of gene pairs along with the coordinates of the gene pairs and the protein sequence similarity between a protein pair to identify chains of genes with maximal sequence similarity and identical gene order. By optimizing a score comprised of both colinearity and sequence similarity, DAGchainer identifies protein pairs most likely to be true orthologs. BLASTP comparisons using 1e-5 as an E-value cut-off were also used as input into TribeMCL for clustering. Protein sequence clusters with members from only a single species were defined as species-specific proteins. Percent GC and percent GC3 contents in genome and gene-coding sequences were calculated using scripts. RSCU values were calculated using the CodonW program. Creation of heat maps and HCL and PCA clustering were done using MultiExperiment Viewer (MEV v4.7.4).

\section{Phylogenetic analysis.}

The multigene phylogenetic trees were conducted based on the concatenated sequences of core genes identified by the CEGMA pipeline. The 293 core genes found in all 12 analyzed genomes were first aligned one by one using MAFFT (v7.221) and its "L-INS-I" and "auto" parameters for protein and DNA sequences, respectively. PartitionFinder (v1.1.1) was used to select best-fit partitioning schemes and models of molecular evolution for nucleotide and aa alignments, respectively. Based on the obtained results, we performed RaxML (v8.1.21) to construct trees, using the ML + rapid bootstrap method (-f a) and 200 bootstrap repeats. $S$. parasitica was set as outgroup. A similar method was used to construct the mitochondrial and nuclear multilocus phylogenetic trees for a larger number of Phytophthora species. Pythium ultimum was set as outgroup. The other phylogenetic trees were constructed by the neighbor-joining method, using MEGA software (v5.10) or by the maximum-likelihood method using PHYML implemented in Seaview (v4.4). All of the trees were viewed using MEGA.

\section{Transient expression of NLP proteins in $N$. benthamiana.}

Full-length NLP genes, including the signal peptide coding region, were amplified from $P$. litchii or $P$. sojae genomic DNA by polymerase chain reaction (PCR), using high-fidelity DNA polymerase (TaKaRa Inc., Dalian, China) with the indicated primers (Supplementary Table S13). The products were then cloned into PVX vector pGR107. A 3xHA (hemagglutinin) tag was added onto the $\mathrm{C}$-terminus of the NLP coding regions. The constructs were confirmed by sequencing. Recombinant plasmids were maintained and propagated in Escherichia coli JM109, and then, were introduced into Agrobacterium tumefaciens GV3101, using electroporation. A. tumefaciens transformants were grown at $30^{\circ} \mathrm{C}$ on Luria Bertani (LB) agar plates supplemented with kanamycin at $50 \mu \mathrm{g} / \mathrm{ml}$ for 2 days. Colonies were verified by $\mathrm{PCR}$, using vector primers. For infiltration into leaves, recombinant strains of A. tumefaciens were grown in LB media supplemented with kanamycin at $50 \mu \mathrm{g} / \mathrm{ml}$ for 1 day at $30^{\circ} \mathrm{C}$, with constant shaking. The cells were harvested by centrifugation at $5,000 \times g$ for $3 \mathrm{~min}$, and were then washed three times with $1 \mathrm{ml}$ of induction medium (10 mM MES, $10 \mathrm{mM} \mathrm{MgCl}$, and $150 \mathrm{mM}$ acetosyringone, $\mathrm{pH} \mathrm{5.6).} \mathrm{The}$ A. tumefaciens cells were resuspended in induction medium to a final optical density at $600 \mathrm{~nm}$ of 0.4 and were then incubated at room temperature for $3 \mathrm{~h}$, prior to infiltration.

$N$. benthamiana plants were grown in the greenhouse for 4 to 6 weeks at $25^{\circ} \mathrm{C}$ during the day time $(16 \mathrm{~h})$ and $16^{\circ} \mathrm{C}$ at night ( $8 \mathrm{~h})$. The leaves were infiltrated with an A. tumefaciens cell suspension through a syringe without a needle. A. tumefaciens strains harboring green fluorescent protein and $P S N L P 1$ were used as negative and positive controls, respectively. Photos were taken 4 days postinoculation.

For Western blot analysis, $N$. benthamiana total proteins were extracted $48 \mathrm{~h}$ after inoculation, by grinding $400 \mathrm{mg}$ of

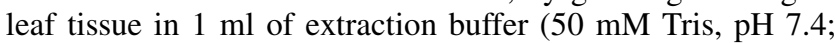
$150 \mathrm{mM} \mathrm{NaCl}$; and $1 \%$ Triton X-100) in the presence of $5 \mu \mathrm{l}$ of protease inhibitor cocktail (P9599; Sigma-Aldrich, St. Louis). Total protein extract samples were loaded on sodium dodecyl sulfate polyacrylamide gel electrophoresis gels using equivalent amounts of protein for each sample in an experiment. After electrophoresis, proteins were transferred from gels to polyvinylidene diflouride membranes. For Western blotting, mouse anti-HA monoclonal antibody (Sigma-Aldrich) and goat antimouse immunoglobulin G-peroxidase conjugate (SigmaAldrich) were used as the primary and secondary antibodies, respectively. The membrane was treated with chemiluminescent peroxidase substrate 1 (Thermo Scientific Pierce, Rockford, IL, U.S.A.) for $2 \mathrm{~min}$. The membrane was briefly drained and exposed to BioMax (Kodak, Rochester, NY, U.S.A.) light film several times (depending on results) for exposure signal development.

\section{ACKNOWLEDGMENTS}

This work was supported by grants to Y. Wang from the Special Fund for Agro Scientific Research in the Public Interest (201303018), China National Funds for Distinguished Young Scientists (31225022), and the International Science \& Technology Cooperation Program of China (2013DFG32030), by grants to W. Ye from the National Natural Science Foundation of China (31401688) and the Natural Science Foundation of Jiangsu Province (BK20140698), and by funding from Oregon State University to B. M. Tyler.

\section{LITERATURE CITED}

Adhikari, B. N., Hamilton, J. P., Zerillo, M. M., Tisserat, N., Lévesque, C. A., and Buell, C. R. 2013. Comparative genomics reveals insight into virulence strategies of plant pathogenic oomycetes. PLoS One 8: e75072.

Ann, P. J., and Ko, W. H. 1984. Blossom blight of litchi in Taiwan caused by Peronophythora litchi. Plant Dis. 68:826.

Ann, P. J., Tsai, J. N., and Yang, H. R. 2012. First report of leaf and stem downy blight of longan seedlings caused by Peronophythora litchii in Taiwan. Plant Dis. 96:1224.

Baxter, L., Tripathy, S., Ishaque, N., Boot, N., Cabral, A., Kemen, E., Thines, M., Ah-Fong, A., Anderson, R., Badejoko, W., Bittner-Eddy, P., Boore, J. L., Chibucos, M. C., Coates, M., Dehal, P., Delehaunty, K., Dong, S., Downton, P., Dumas, B., Fabro, G., Fronick, C., Fuerstenberg, S. I., Fulton, L., Gaulin, E., Govers, F., Hughes, L., Humphray, S., Jiang, R. H., Judelson, H., Kamoun, S., Kyung, K., Meijer, H., Minx, P., Morris, P., Nelson, J., Phuntumart, V., Qutob, D., Rehmany, A., RougonCardoso, A., Ryden, P., Torto-Alalibo, T., Studholme, D., Wang, Y., Win, J., Wood, J., Clifton, S. W., Rogers, J., Van den Ackerveken, G., Jones, J. D., McDowell, J. M., Beynon, J., and Tyler, B. M. 2010. Signatures of adaptation to obligate biotrophy in the Hyaloperonospora arabidopsidis genome. Science 330:1549-1551. 
Boutemy, L. S., King, S. R., Win, J., Hughes, R. K., Clarke, T. A. Blumenschein, T. M., Kamoun, S., and Banfield, M. J. 2011. Structures of Phytophthora RxLR effector proteins: A conserved but adaptable fold underpins functional diversity. J. Biol. Chem. 286:35834-35842.

Bowler, C., Allen, A. E., Badger, J. H., Grimwood, J., Jabbari, K., Kuo, A., Maheswari, U., Martens, C., Maumus, F., Otillar, R. P., Rayko, E., Salamov, A., Vandepoele, K., Beszteri, B., Gruber, A., Heijde, M., Katinka, M., Mock, T., Valentin, K., Verret, F., Berges, J. A., Brownlee, C., Cadoret, J. P., Chiovitti, A., Choi, C. J., Coesel, S., De Martino, A. Detter, J. C., Durkin, C., Falciatore, A., Fournet, J., Haruta, M., Huysman, M. J., Jenkins, B. D., Jiroutova, K., Jorgensen, R. E., Joubert, Y., Kaplan, A., Kroger, N., Kroth, P. G., La Roche, J., Lindquist, E., Lommer, M., Martin-Jezequel, V., Lopez, P. J., Lucas, S., Mangogna, M., McGinnis, K., Medlin, L. K., Montsant, A., Oudot-Le Secq, M. P. Napoli, C., Obornik, M., Parker, M. S., Petit, J. L., Porcel, B. M., Poulsen, N., Robison, M., Rychlewski, L., Rynearson, T. A., Schmutz, J., Shapiro, H., Siaut, M., Stanley, M., Sussman, M. R., Taylor, A. R., Vardi, A., von Dassow, P., Vyverman, W., Willis, A., Wyrwicz, L. S., Rokhsar, D. S., Weissenbach, J., Armbrust, E. V., Green, B. R., Van de Peer, Y., and Grigoriev, I. V. 2008. The Phaeodactylum genome reveals the evolutionary history of diatom genomes. Nature 456:239-244.

Chen, C. C. 1961. A species of Peronophythora gen. nov. parasitic on litchi fruit in Taiwan. Pages 1-37 in Special Publication of College of Agriculture, Vol 10. National Taiwan University, Chinese Taipei.

Chi, P. K., Pang, X. P., and Liu, R. 1982. Studies on Phytophthora disease of litchi. 1. Identification of causal agent. Pages 72-73 in: Proceedings of the Annual Meeting of the Chinese Phytopathological Society. Chinese Society of Plant Pathology, Beijing.

Crane, J. H., Balerdi, C. F., and Maguire, I. 2005. Lychee growing in the Florida home landscape. Florida Cooperative Extension Service Factsheet HS-6. edis. ifas. ufl.edu/mg051. The Institute of Food and Agricultural Sciences, University of Florida, Gainesville, FL, U.S.A.

Dean, R. A., Talbot, N. J., Ebbole, D. J., Farman, M. L., Mitchell, T. K., Orbach, M. J., Thon, M., Kulkarni, R., Xu, J. R., Pan, H., Read, N. D., Lee, Y. H., Carbone, I., Brown, D., Oh, Y. Y., Donofrio, N., Jeong, J. S., Soanes, D. M., Djonovic, S., Kolomiets, E., Rehmeyer, C., Li, W. Harding, M., Kim, S., Lebrun, M. H., Bohnert, H., Coughlan, S., Butler, J., Calvo, S., Ma, L. J., Nicol, R., Purcell, S., Nusbaum, C., Galagan, J. E., and Birren, B. W. 2005. The genome sequence of the rice blast fungus Magnaporthe grisea. Nature 434:980-986.

Derevnina, L., Reyes-Chin Wo, S., Martin, F., Wood, K., Froenicke, L., Spring, O., and Michelmore, R. W. 2015. Genome sequence and architecture of the tobacco downy mildew pathogen, Peronospora tabacina. Mol. Plant-Microbe Interact 28:1198-1215.

Dong, S., Kong, G., Qutob, D., Yu, X., Tang, J., Kang, J., Dai, T., Wang, H., Gijzen, M., and Wang, Y. 2012. The NLP toxin family in Phytophthora sojae includes rapidly evolving groups that lack necrosis-inducing activity. Mol. Plant-Microbe Interact 25:896-909.

Enright, A. J., Kunin, V., and Ouzounis, C. A. 2003. Protein families and TRIBES in genome sequence space. Nucleic Acids Res. 31 : 4632-4638.

Gijzen, M., and Nurnberger, T. 2006. Nep1-like proteins from plant pathogens: Recruitment and diversification of the NPP1 domain across taxa. Phytochemistry 67:1800-1807.

Göker, M., Voglmayr, H., Riethmüller, A., and Oberwinkler, F. 2007. How do obligate parasites evolve? A multi-gene phylogenetic analysis of downy mildews. Fungal Genet. Biol. 44:105-122.

Haas, B. J., Kamoun, S., Zody, M. C., Jiang, R. H., Handsaker, R. E., Cano, L. M., Grabherr, M., Kodira, C. D., Raffaele, S., Torto-Alalibo, T., Bozkurt, T. O., Ah-Fong, A. M., Alvarado, L., Anderson, V. L., Armstrong, M. R., Avrova, A., Baxter, L., Beynon, J., Boevink, P. C., Bollmann, S. R., Bos, J. I., Bulone, V., Cai, G., Cakir, C., Carrington, J. C., Chawner, M., Conti, L., Costanzo, S., Ewan, R., Fahlgren, N., Fischbach, M. A., Fugelstad, J., Gilroy, E. M., Gnerre, S., Green, P. J., Grenville-Briggs, L. J., Griffith, J., Grunwald, N. J., Horn, K., Horner, N. R., Hu, C. H., Huitema, E., Jeong, D. H., Jones, A. M., Jones, J. D., Jones, R. W., Karlsson, E. K., Kunjeti, S. G., Lamour, K., Liu, Z., Ma, L., Maclean, D., Chibucos, M. C., McDonald, H., McWalters, J., Meijer, H. J., Morgan, W., Morris, P. F., Munro, C. A., O’Neill, K., OspinaGiraldo, M., Pinzon, A., Pritchard, L., Ramsahoye, B., Ren, Q., Restrepo, S., Roy, S., Sadanandom, A., Savidor, A., Schornack, S., Schwartz, D. C., Schumann, U. D., Schwessinger, B., Seyer, L., Sharpe, T., Silvar, C., Song, J., Studholme, D. J., Sykes, S., Thines, M., van de Vondervoort, P. J., Phuntumart, V., Wawra, S., Weide, R., Win, J., Young, C., Zhou, S., Fry, W., Meyers, B. C., van West, P., Ristaino, J., Govers, F., Birch, P. R., Whisson, S. C., Judelson, H. S., and Nusbaum, C. 2009. Genome sequence and analysis of the Irish potato famine pathogen Phytophthora infestans. Nature 461:393-398.
Ho, H. H., Lu, J. Y., and Gong, L. Y. 1984. Observations on sexual reproduction by Peronophythora litchii. Mycologia 76:745-747.

Huang, H., Wang, C. P., and Xu, D. Y. 1983. On Peronophythora litchii. Acta Mycol. Sin. 2:201-206.

Jiang, R. H., de Bruijn, I., Haas, B. J., Belmonte, R., Lobach, L., Christie, J., van den Ackerveken, G., Bottin, A., Bulone, V., Diaz-Moreno, S. M., Dumas, B., Fan, L., Gaulin, E., Govers, F., Grenville-Briggs, L. J., Horner, N. R., Levin, J. Z., Mammella, M., Meijer, H. J., Morris, P., Nusbaum, C., Oome, S., Phillips, A. J., van Rooyen, D., Rzeszutek, E., Saraiva, M., Secombes, C. J., Seidl, M. F., Snel, B., Stassen, J. H., Sykes, S., Tripathy, S., van den Berg, H., Vega-Arreguin, J. C., Wawra, S. Young, S. K., Zeng, Q., Dieguez-Uribeondo, J., Russ, C., Tyler, B. M., and van West, P. 2013. Distinctive expansion of potential virulence genes in the genome of the oomycete fish pathogen Saprolegnia parasitica. PLoS Genet. 9:e1003272.

Jiang, R. H., Tripathy, S., Govers, F., and Tyler, B. M. 2008. RXLR effector reservoir in two Phytophthora species is dominated by a single rapidly evolving superfamily with more than 700 members. Proc. Natl. Acad. Sci. U.S.A. 105:4874-4879.

Joneson, S., Stajich, J. E., Shiu, S. H., and Rosenblum, E. B. 2011. Genomic transition to pathogenicity in chytrid fungi. PLoS Pathog. 7:e1002338.

Ko, W. H., Chang, H. S., Su, H. J., Chen, C. C., and Leu, L. S. 1978. Peronophythoraceae, a new family of Peronosporales. Mycologia 70:380-384.

Kroon, L. P., Brouwer, H., de Cock, A. W., and Govers, F. 2012. The genus Phytophthora anno 2012. Phytopathology 102:348-364.

Lamour, K., Mudge, J., Gobena, D., Hurtado-Gonzales, O. P., Schmutz, J. Kuo, A., Miller, N. A., Rice, B. J., Raffaele, S., Cano, L., Bharti, A. K, Donahoo, R. S., Finley, S. L., Huitema, E., Hulvey, J., Platt, D., Salamov, A., Savidor, A., Sharma, R., Stam, R., Storey, D., Thines, M., Win, J., Haas, B., Dinwiddie, D., Jenkins, J., Knight, J., Affourtit, J., Han, C. S., Chertkov, O. Lindquist, E. A., Detter, C., Grigoriev, I. V., Kamoun, S., and Kingsmore, S. F. 2012. Genome sequencing and mapping reveal loss of heterozygosity as a mechanism for rapid adaptation in the vegetable pathogen Phytophthora capsici. Mol. Plant-Microbe Interact 25:1350-1360.

Lévesque, C. A., Brouwer, H., Cano, L., Hamilton, J. P., Holt, C., Huitema E., Raffaele, S., Robideau, G. P., Thines, M., Win, J., Zerillo, M. M. Beakes, G. W., Boore, J. L., Busam, D., Dumas, B., Ferriera, S., Fuerstenberg, S. I., Gachon, C. M., Gaulin, E., Govers, F., GrenvilleBriggs, L., Horner, N., Hostetler, J., Jiang, R. H., Johnson, J., Krajaejun, T., Lin, H., Meijer, H. J., Moore, B., Morris, P., Phuntmart, V., Puiu, D., Shetty, J., Stajich, J. E., Tripathy, S., Wawra, S., van West, P., Whitty, B. R., Coutinho, P. M., Henrissat, B., Martin, F., Thomas, P. D., Tyler, B. M., De Vries, R. P., Kamoun, S., Yandell, M., Tisserat, N., and Buell, C. R. 2010. Genome sequence of the necrotrophic plant pathogen Pythium ultimum reveals original pathogenicity mechanisms and effector repertoire. Genome Biol. 11:R73.

Martin, F. N., Blair, J. E., and Coffey, M. D. 2014. A combined mitochondrial and nuclear multilocus phylogeny of the genus Phytophthora. Fungal Genet. Biol. 66:19-32.

Mitra, S., and Pathak, P. 2008. Litchi production in the Asia-Pacific region. Acta Hort. 863:29-36.

Morton, J. F. 1987. Fruits of warm climates. Center for New Crops \& Plant Products, Purdue University, West Lafayette, IN, U.S.A

Riethmüller, A., Voglmayr, H., Göker, M., Weiß, M., and Oberwinkler, F. 2002. Phylogenetic relationships of the downy mildews (Peronosporales) and related groups based on nuclear large subunit ribosomal DNA sequences. Mycologia 94:834-849.

Runge, F., Telle, S., Ploch, S., Savory, E., Day, B., Sharma, R., and Thines, M. 2011. The inclusion of downy mildews in a multi-locus-dataset and its reanalysis reveals a high degree of paraphyly in Phytophthora. IMA Fungus 2:163-171.

Sambles, C., Schlenzig, A., O’Neill, P., Grant, M., and Studholme, D. J. 2015. Draft genome sequences of Phytophthora kernoviae and Phytophthora ramorum lineage EU2 from Scotland. Genom. Data 6:193-194.

Sharma, R., Xia, X., Cano, L. M., Evangelisti, E., Kemen, E., Judelson, H., Oome, S., Sambles, C., van den Hoogen, D. J., Kitner, M., Klein, J., Meijer, H. J., Spring, O., Win, J., Zipper, R., Bode, H. B., Govers, F. Kamoun, S., Schornack, S., Studholme, D. J., Van den Ackerveken, G., and Thines, M. 2015. Genome analyses of the sunflower pathogen Plasmopara halstedii provide insights into effector evolution in downy mildews and Phytophthora. BMC Genomics 16:741.

Spanu, P. D., Abbott, J. C., Amselem, J., Burgis, T. A., Soanes, D. M., Stuber, K., Ver Loren van Themaat, E., Brown, J. K., Butcher, S. A., Gurr, S. J., Lebrun, M. H., Ridout, C. J., Schulze-Lefert, P., Talbot, N. J., Ahmadinejad, N., Ametz, C., Barton, G. R., Benjdia, M., Bidzinski, P., Bindschedler, L. V., Both, M., Brewer, M. T., Cadle-Davidson, L., CadleDavidson, M. M., Collemare, J., Cramer, R., Frenkel, O., Godfrey, D., Harriman, J., Hoede, C., King, B. C., Klages, S., Kleemann, J., Knoll, D. 
Koti, P. S., Kreplak, J., Lopez-Ruiz, F. J., Lu, X., Maekawa, T., Mahanil, S., Micali, C., Milgroom, M. G., Montana, G., Noir, S., O'Connell, R. J., Oberhaensli, S., Parlange, F., Pedersen, C., Quesneville, H., Reinhardt, R., Rott, M., Sacristan, S., Schmidt, S. M., Schon, M., Skamnioti, P., Sommer, H., Stephens, A., Takahara, H., Thordal-Christensen, H., Vigouroux, M., Wessling, R., Wicker, T., and Panstruga, R. 2010. Genome expansion and gene loss in powdery mildew fungi reveal tradeoffs in extreme parasitism. Science 330:1543-1546.

Tyler, B. M., Tripathy, S., Zhang, X., Dehal, P., Jiang, R. H., Aerts, A., Arredondo, F. D., Baxter, L., Bensasson, D., Beynon, J. L., Chapman, J., Damasceno, C. M., Dorrance, A. E., Dou, D., Dickerman, A. W., Dubchak, I. L., Garbelotto, M., Gijzen, M., Gordon, S. G., Govers, F., Grunwald, N. J., Huang, W., Ivors, K. L., Jones, R. W., Kamoun, S., Krampis, K., Lamour, K. H., Lee, M. K., McDonald, W. H., Medina, M., Meijer, H. J., Nordberg, E. K., Maclean, D. J., Ospina-Giraldo, M. D., Morris, P. F., Phuntumart, V., Putnam, N. H., Rash, S., Rose, J. K., Sakihama, Y., Salamov, A. A., Savidor, A., Scheuring, C. F., Smith, B. M., Sobral, B. W., Terry, A., Torto-Alalibo, T. A., Win, J., Xu, Z., Zhang, H., Grigoriev, I. V., Rokhsar, D. S., and Boore, J. L. 2006. Phytophthora genome sequences uncover evolutionary origins and mechanisms of pathogenesis. Science 313:1261-1266.

Vien, N., Benyon, F. H. L., Trung, H., Summerell, B. A., Van, N., and Burgess, L. W. 2001. First record of Peronophythora litchii on litchi fruit in Vietnam. Australas. Plant Pathol. 30:287-288.

Voglmayr, H. 2003. Phylogenetic relationships of Peronospora and related genera based on nuclear ribosomal ITS sequences. Mycol. Res. 107:1132-1142.

Wang, H., Sun, H., Stammler, G., Ma, J., and Zhou, M. 2010. Generation and characterization of isolates of Peronophythora litchii resistant to carboxylic acid amide fungicides. Phytopathology 100:522-527.

Waterhouse, G. M. 1973. Peronosporales. Pages 165-183 in: The Fungi: An advanced treatise. Vol. 4B. ATaxonomic Review with Keys: Basidiomycetes and lower fungi. G. C. Ainsworth, F. K. Sparrow, and A. S. Sussman, eds. Academic Press, New York.

Ye, W., Wang, Y., and Wang, Y. 2015. Bioinformatics analysis reveals abundant short alpha-helices as a common structural feature of oomycete RxLR effector proteins. PLoS One 10:e0135240.
Zhang, Z., Zheng, X., Wang, Y., and Ko, W. H. 2007. Evaluation of the rearrangement of taxonomic position of Peronophythora litchii based on partial DNA sequences. Bot. Stud. 48:79-89.

\section{AUTHOR-RECOMMENDED INTERNET RESOURCES}

Augustus gene prediction database:

http://bioinf.uni-greifswald.de/augustus

Broad Institute database: http://www.broadinstitute.org

CodonW program: http://codonw.sourceforge.net

DAGchainer software: http://dagchainer.sourceforge.net

dbCAN database: http://csbl.bmb.uga.edu/dbCAN

Department of Energy Joint Genome Institute (JGI) database: http://genome.jgi.doe.gov

EMBL-EBI Pfam database: http://pfam.xfam.org

Eumicrobedb database: http://eumicrobedb.org

HMMER3 software: http://hmmer.janelia.org

JGI Phytophthora sojae v3.0 portal: http://genome.jgi.doe.gov/Physo3

The Korf Lab, University of California-Davis: http://korflab.ucdavis.edu

MAFFT multiple sequence alignment program:

http://mafft.cbrc.jp/alignment/software

MEGA software: http://megasoftware.net

MultiExperiment Viewer: http://www.tm4.org/mev.html

National Center for Biotechnology Information GenBank database: http://www.ncbi.nlm.nih.gov/nuccore

Pythium genome database: http://pythium.plantbiology.msu.edu

Seaview graphical user interface:

http://pbil.univ-lyon1.fr/software/seaview.html

SignalP 3.0 server: http://www.cbs.dtu.dk/services/SignalP-3.0

SOAPaligner software: http://soap.genomics.org.cn/soapaligner.html

SOAPdenovo assembly method:

http://soap.genomics.org.cn/soapdenovo.html

SSPACE bioinformatic solutions:

http://www.baseclear.com/bioinformatics-tools

TMHMM 2.0 server: http://www.cbs.dtu.dk/services/TMHMM

Weblogo website: http://weblogo.threeplusone.com 